\title{
FLAGELLOSCYPHA MINUTISSIMA (BASIDIOMYCETES), A NEW FOR POLAND MINUTE CYPHELLACEOUS FUNGUS
}

\author{
Marcin PiąteK ${ }^{1}$, Jolanta CABAŁA ${ }^{2}$ \\ ${ }^{1}$ Department of Mycology and ${ }^{2}$ Department of Phycology \\ W. Szafer Institute of Botany, Polish Academy of Sciences \\ Lubicz 46, 31-512 Cracow, Poland \\ e-mail: mpiatek@ib-pan.krakow.pl
}

(Received: October 30, 2003. Accepted: January 22, 2004)

\begin{abstract}
The first records of Flagelloscypha minutissima (Burt) Donk are reported from Poland, being easternmost on the European continent. A brief description and illustration of the species based on Polish specimens are given and its ecology, distribution, and taxonomy are surveyed.
\end{abstract}

KEY WORDS: Agaricales, Marasmiaceae, cyphellaceous fungi, mycogeography, Poland, Europe.

\section{INTRODUCTION}

Cyphellaceous fungi are poorly investigated in Poland similar as in other European and non-European countries. Theirs minute size and overall similarity to discomycetes are the main reasons for that. In Poland altogether no fewer than 18 species of cyphellaceous fungi have been detected. They belong to the following genera (in parentheses the number of species occurring in Poland is given): Calyptella Quél. (4), Chromocyphella De Toni and Levi (1), Cyphella Fr. (1), Cyphellopsis Donk (2), Cyphellostereum D. A. Reid (1), Flagelloscypha Donk (1), Henningsomyces Kuntze (1), Merismodes Earle (1), Lachnella Fr. (2), Nochascypha Agerer (1), Rectipilus Agerer (1), Stigmatolemma Kalchbr. (1), and Woldmaria W.B. Cooke (1). The genus Flagelloscypha was represented only by Flagelloscypha kavinae (Pilát) W.B. Cooke, being known from altimontane elevations of Babia Góra Mt (Bujakiewicz 1993). Recently another representative of this genus, Flagelloscypha minutissima (Burt) Donk, has been recorded during studying the corticioid and polyporoid fungi of Tarnów town in southern Poland. A description and illustrations of this species are given below.

\section{RESULTS AND DISCUSSION}

Flagelloscypha minutissima (Burt) Donk, Lilloa 22: 312. 1951 (1949) (Figs 1-2)

Basidiomes annual, cupulate, sessile to short-stalked, small, up to $1 \mathrm{~mm}$ in diam., white, outer surface shortly haired, when moist the margin exposes the hymenium, and when dry the margin is draped and covers the hymenium; marginal hairs thick-walled, encrusted by rhombical crystals, upper part non-encrusted, thin-walled, ending with curved flagellum; hyphal system monomitic, hyphae with clamps, branched, up to $4 \mu \mathrm{m}$ wide; basidia broadly clavate, with 2 sterigmata and basal clamp, 20-30 × 5-6 um; basidiospores citriform, elliptic to navicular, smooth, hyaline, non amyloid, 7.0-9.0 × 3.5-4.5 $\mu \mathrm{m}$.

Specimens examined. Poland. Sandomierz Basin: Tarnów, on the River Dunajec near E. Kwiatkowski street, fallen branch of Fraxinus excelsior, 8 Aug. 2002, leg. M. Piątek, KRAM F-52540; Tarnów, at the E. Kwiatkowski street, fallen branch of Robinia pseudoacacia, 8 Aug. 2002, leg. M. Piątek, KRAM F-52539; Tarnów, Krzyskie Forests, at Ścieżki street, fallen branch of Fraxinus excelsior, 16 May 2001, leg. M. Piątek, KRAM F-51524; Tarnów, Piaskówka, at Elektryczna street, fallen branch of deciduous tree, 23 Aug. 2000, leg. M. Piątek, KRAM F-52519.

This taxon has been recorded by Agerer (1975) as nonhost-specific species occurring on various trees, herbs and fungus Phellinus ferruginosus (Schrad.: Fr.) Bourdot and Galzin. In Poland it was collected in remnants of riverine forest, deciduous and mixed forests strongly changed by human activity, and in roadside covered by ruderal herb community. Basidiomes occurred both on wood and bark of fallen branches of Fraxinus excelsior, Robinia pseudoacacia and unidentified deciduous tree.

In Europe Flagelloscypha minutissima has numerous stations in Austria, Germany, and Czech Republic, and it occurs rarely in France, Italy, Switzerland (Agerer 1975), 


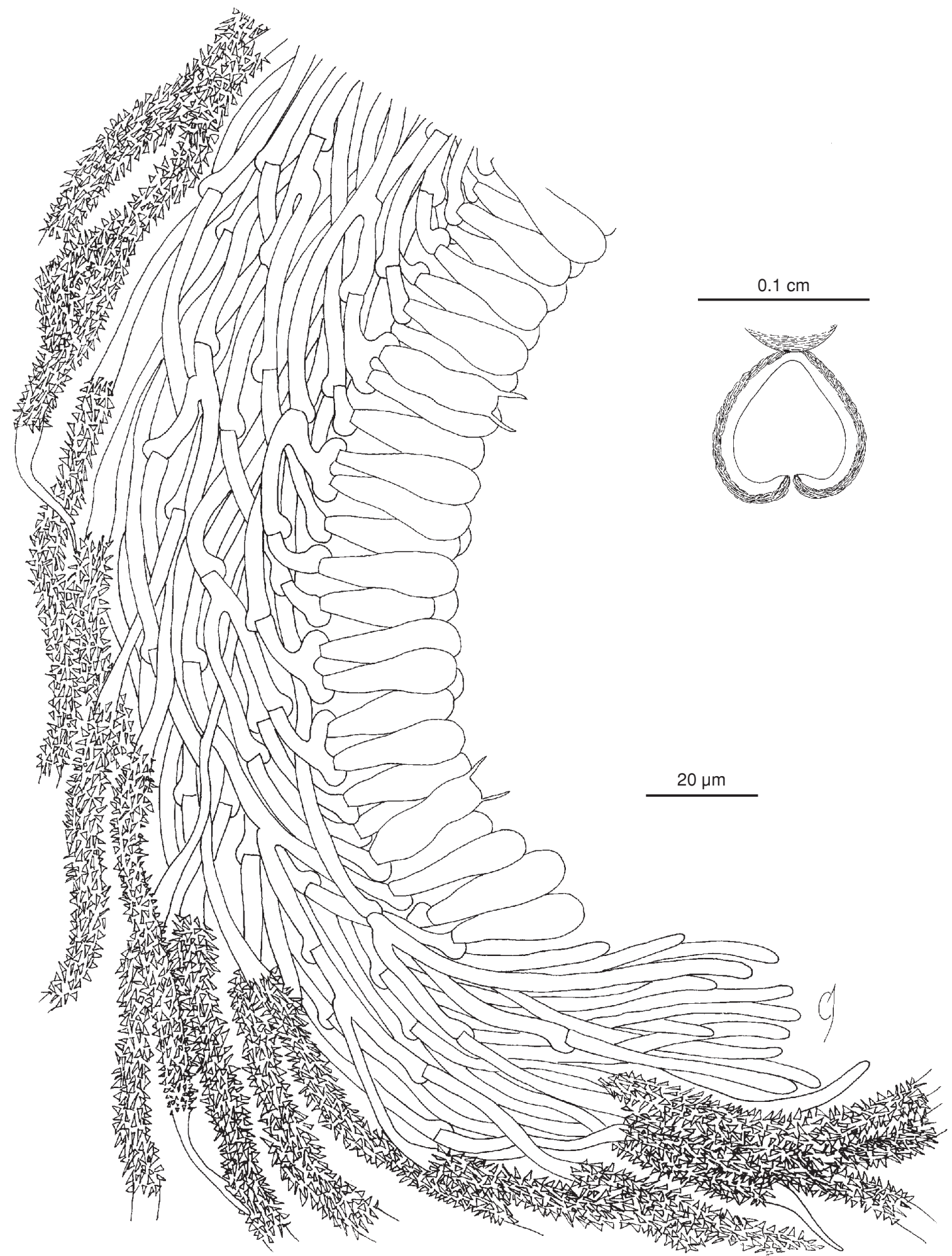

Fig. 1. Flagelloscypha minutissima (Burt) Donk: cross section of basidiome with hymenium and outer haired surface.

Denmark (Hansen and Knudsen 1992), and Great Britain (Blackwell 2003). Outside Europe this fungus has been found in Venezuela (Agerer 1975), United States (Agerer 1975; Ginns and Lefebvre 1993), and Canada (Ginns and Lefebvre 1993). The four Polish localities are situated in Tarnów town (Fig. 3) in southern part of the country and represent nice range extension of Flagelloscypha minutissi$m a$, being easternmost in the European continent. This wo- uld not seem to be the final number of known localities in Poland and future additions are likely as more collections of cyphellaceous fungi are encountered and examined.

The genus Flagelloscypha comprises 33 species (Agerer 1975, 1979a-c, 1980, 1983, 2002; Agerer and Schmid-Heckel 1986). In theirs 'Dictionary of the fungi' Kirk et al. (2001) mentioned 10 species known in this genus, but evidently it is a mistake. Flagelloscypha is characterized by 


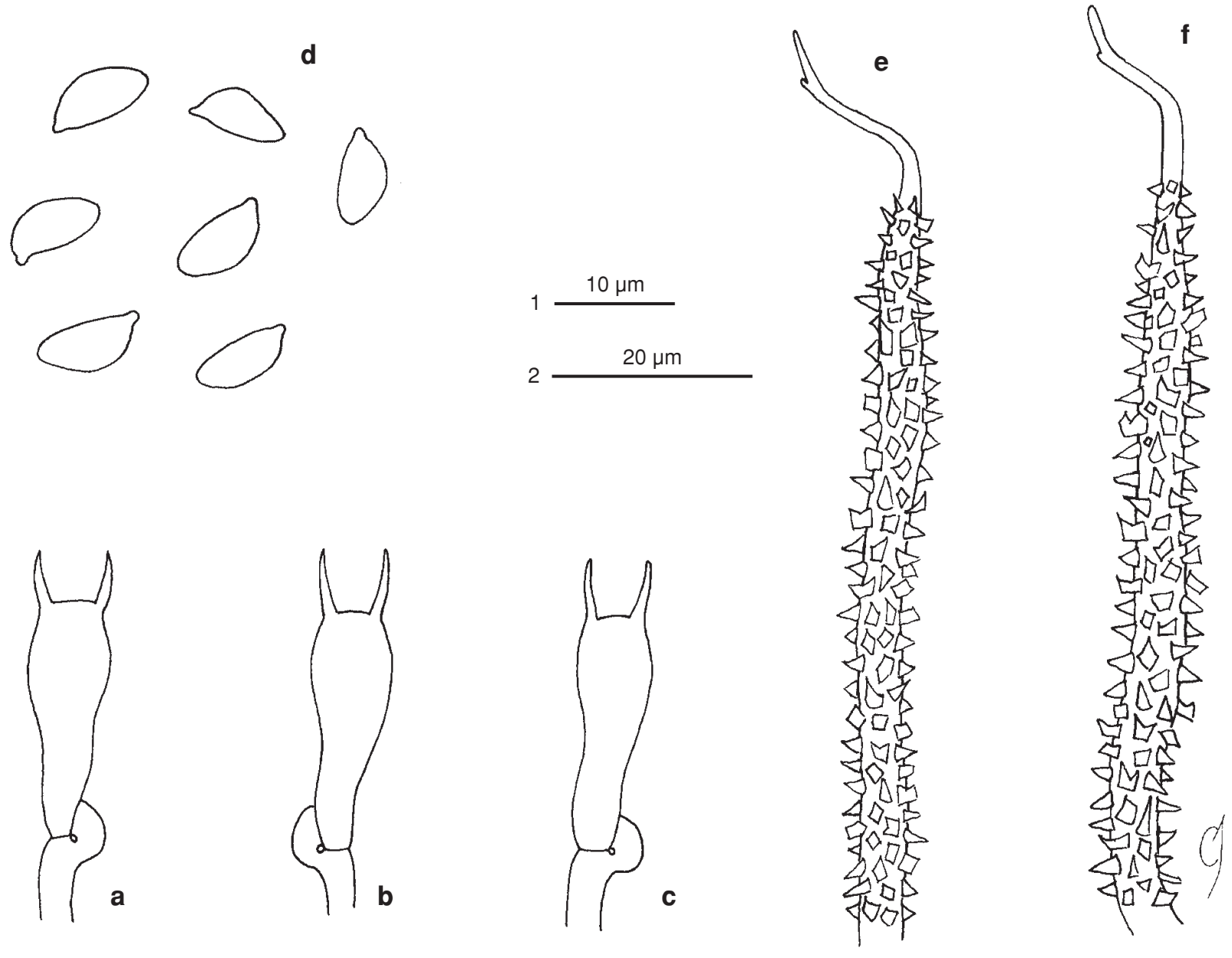

Fig. 2. Flagelloscypha minutissima (Burt) Donk: a-c - basidia; d - basidiospores; e-f - marginal hairs; scale bars: 1 - d; 2 - a-c and e-f.

small cupulate basidiomes with hairs encrusted by acicular to rhombical crystals and narrow, non-encrusted apical part, lacks of cystidia or other sterile elements, and basidia mostly shorter than $30 \mu \mathrm{m}$, with 2-4 sterigmata. Flagelloscypha minutissima is immediately identified by its basidia with 2 sterigmata, and citriform, elliptic to navicular basidiospores, mostly 7.0-10.0 × 3.5-4.5 $\mu \mathrm{m}$. The group of 2 sterigmate Flagelloscypha, apart from $F$. minutissima, is represented by three other species $F$. christinae Agerer, $F$. faginea (Lib.) W.B. Cooke, and F. oblongispora Agerer. Of these, F. faginea, a widespread Northern Hemisphere temperate species, is distinct at first glance because its asymmetrically-oval to lacrimoid basidiospores, mostly 9.0-13.0 × 3.0-4.5 um (Agerer 1975), while F. oblongispo$\mathrm{ra}$, known from Colombia, is at once distinguished from all other species of this group by its asymmetrically-elliptic basidiospores, mostly 8.5-10.0 × 4.0-5.5 um (Agerer 1980). Finally, F. christinae, known only from the type locality in Italy, differs in having characteristic suburniform basidia with distinct capitate upper part, slightly larger basidiospores, mostly 9.0-12.0 × 4.0-5.5 $\mu \mathrm{m}$, and forming basidiomes in colonies (Agerer 1975).

\section{ACKNOWLEDGEMENTS}

This study was supported by the State Committee for Scientific Research (KBN), grant 6 P04G 03418.

\section{LITERATURE CITED}

AGERER R. 1975. Flagelloscypha. Studien an cyphelloiden Basidiomyceten. Sydowia 27: 131-265.

AGERER R. 1979a. Flagelloscypha sect. Lachnelloscypha, a link between the genera Lachnella and Flagelloscypha. Persoonia 10: $337-346$.

AGERER R. 1979b. A new combination in the genus Flagelloscypha and a contribution to the identity of Cyphella peckii. Mycotaxon 9: 464-468.

AGERER R. 1979c. Typusstudien an cyphelloiden Pilzen. III. Flagelloscypha orthospora, F. pseudopanax, F. tongariro. Sydowia 32: 5-12.

AGERER R. 1980. Contribution to neotropical cyphellaceous fungi. I. Three new species of Flagelloscypha. Mycologia 72: 908-915.

AGERER R. 1983. Typusstudien an cyphelloiden Pilzen IV. Lachnella Fr. s. 1. Mitt. Bot. München 19: 163-334.

AGERER R. 2002. Flagelloscypha crassipilata sp. nov., a species from Peru with extremely thick surface hyphae and big basidia. Mycological Progress 1: 225-228.

AGERER R., SCHMID-HECKEL H. 1986. Typusstudien an cyphelloiden Pilzen V. Flagelloscypha merxmuelleri spec. nov. Z. Mykol. 52: 251-254.

BLACKWELL T. 2003. Recorder's report, September 2002-February 2003. In: Herefordshire Fungus Survey Group. News Sheet No. 5: Spring 2003. http://www.britmycolsoc.org.uk/files/HFSG_newsletter05.pdf

BUJAKIEWICZ A. 1993. Fungi of the alpine and subalpine zones of the Babia Góra Massif. In: D.N. Pegler, L. Boddy, B. 

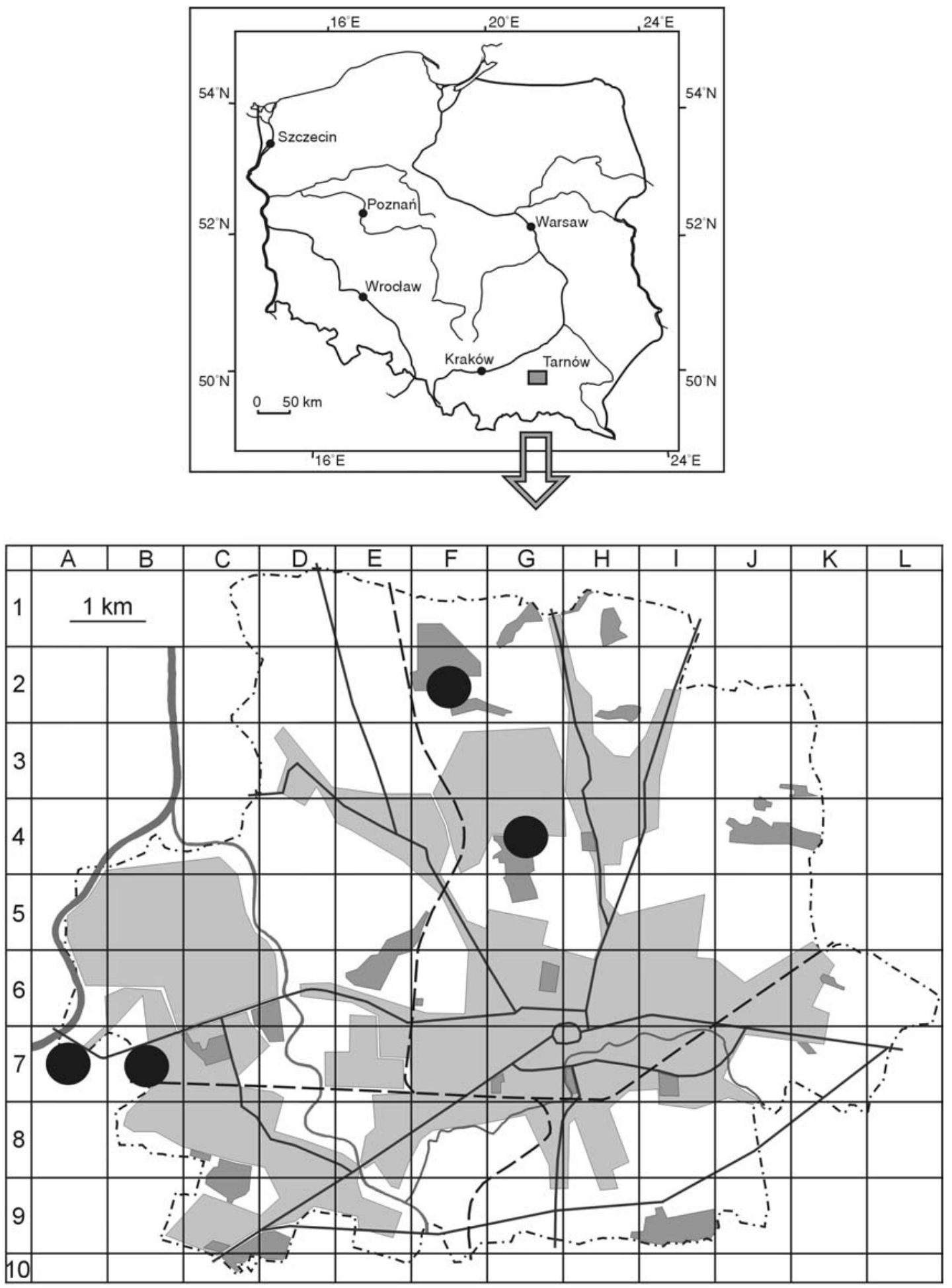

a $\mathrm{b}$ c

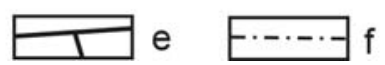

Fig. 3. Location in Poland and distribution of Flagelloscypha minutissima (Burt) Donk in Tarnów town; a - forests and parks; b - built-up area; c - rivers; $\mathrm{d}$ - railway; e - roads; $\mathrm{f}$ - city border.

Ing, P.M. Kirk (eds): Fungi of Europe: Investigation, recording and conservation: pp. 115-120. Royal Botanic Gardens, Kew.

GINNS J., LEFEBVRE M.N.L. 1993. Lignicolous corticioid fungi of North America. Systematics, distribution, and ecology. Mycologia Mem. 19: 1-247.
HANSEN L., KNUDSEN H. 1992. Nordic macromycetes. 2. Polyporales, Boletales, Agaricales, Russulales. Nordsvamp, Copenhagen.

KIRK P.M., CANNON P.F., DAVID J.C., STALPERS J.A. 2001. Ainsworth and Bisby's Dictionary of Fungi. CAB International, Wallingford. 